\title{
Literaturas Africanas e formulações pós-coloniais, de Ana Mafalda Leite
}

\author{
Laura Cavalcante Padilha \\ Universidade Federal Fluminense
}

universo crítico formado no âmbito dos estudos literários, cujo objeto são as literaturas produzidas nos países africanos de língua oficial portuguesa, vem crescendo em consistência e rigor metodológico nas últimas décadas. Cada vez mais os especialistas se valem de um aparato teórico que serve como agente propulsor de suas investigações. Este é o caso de Literaturas Africanas e formulações pós-coloniais de Ana Mafalda Leite que, nascendo já como uma obra clássica, vem juntar-se ao significativo caminho até aqui percorrido pela professora-ensaísta e que tem como paragens obrigatórias: A poética de José Craveirinha (1991), A modalização épica nas literaturas africanas (1995) e Oralidades \& escritas nas literaturas africanas (1998), para além de outros ensaios e publicações. A tudo isso se soma ainda a sua produção poética.

Com suas formulaçoes pós-coloniais, a autora já agora cobre, com profunda acuidade teórico-crítica uma área que demandava um olhar mais atento e reflexivo em nosso âmbito de pesquisa. A obra contém 11 ensaios apresentados em 4 partes: "Literaturas africanas e pós-colonialismo" que funciona como uma introdução balizadora para as demais; "Configurações textuais da oralidade no "cânone moçambicano", quando a ensaísta retoma uma via já aberta por suas Oralidades \& escritas; "Questionação do cânone histórico colonial", momento suspensivo em que deixa Moçambique e se debruça sobre dois romances angolanos; e "Percursos pós-coloniais da poesia moçambicana".

Os textos que se seguem à introdução, de certo modo, por ela se soldam entre si, já que a reflexão inaugural da autora serve como o grande mote da obra, uma espécie de convite, como se dá no jogo milenar da oralidade africana, para que o palco do imaginário, já agora do leitor, se abra. Tal mote funciona como a fórmula prazerosa. "Karingana wa karingana" no conjunto do 
livro crítico. Este consistente ensaio tem o inequívoco mérito de pôr em discussão o termo "pós-colonial" - a partir de sua matriz inglesa - que é, segundo as próprias palavras da professora, um termo "usado pela crítica, em diversas áreas de estudo, para discutir os efeitos culturais da colonização".A seguir, ela demonstra que o seu interesse reside em analisar, em um primeiro momento, os vetores dessa crítica que tem como ponto básico a desconstrução da rigidez cêntrica do olhar colonial, propondo-se uma visão outra pela qual se tentam estabelecer novas negociações de sentido. O seu propósito mais direto é, partindo disso, estender o recorte de tais vetores para o nosso próprio objeto de estudo, ou seja, as literaturas africanas que têm o português como seu veículo principal de expressão, embora sem abdicar muitas vezes, de uma corrosão de base resultante dos vários entrecruzamentos lingüísticos.

De modo claro e didático, Ana Mafalda parte de uma análise do termo póscolonialismo, mostrando-lhe a origem anglo-saxônica, percorrendo os caminhos de sua trajetória histórica e analisando a complexidade e abrangência dos estudos pós-coloniais, cujas formulações básicas seus próprios ensaios sobre obras concretas irão pouco a pouco retomando e, pela repetição, ampliando significativamente. Retornarão, nos ensaios subseqüentes, portanto, questões ligadas a uma "poética da cultura", como as referentes a cânone (retomado na $2^{\mathrm{a}}$ parte), valor, sentido, hibridação, história, diferença, lugar, identidade, etc.

Com Boaventura de Sousa Santos, um de seus interlocutores teóricos para a questão, a crítica tenta analisar o que chama de "Particularidades da colonização portuguesa". Retoma, então, de um lado, a dicotomia Próspero e Caliban, de matriz shakespereana, que se revelará muito produtiva em alguns dos ensaios e, de outro, as diferenças do processo colonial português, tal como as recorta aquele autor. A língua é um dos pontos mais focados pela visão crítica da pesquisadora, assim como o diálogo que se estabelece com as matrizes da tradição local e as rupturas que, por conseqüência, ganham força e lugar.

Vale a pena ainda sublinhar a importância que as reflexões sobre duas questões particularmente representativas para nós, estudiosos dessas literaturas, adquirem em nosso trabalho cotidiano: a do cânone e a do valor. Para além delas é igualmente importante a rediscussão sobre outra questão, isto é, a visão das noções de centro e periferia, com todos os desdobramentos que isso traz, quando pensamos categorias como as de gênero; regionalização; legitimação. A urgência dentre outras de se produzirem novas histórias lite- 
rárias nacionais, bem como antologias que dêem conta do percurso de tais literaturas, sobretudo no que respeita aos séculos passados é também um ponto a sublinhar. A discussão, por fim, sobre hibridez e o processo básico de transculturação leva ao questionamento do conceito de lusofonia que tem na língua seu principal elemento de sustentação. E a autora conclui essa parte, e já agora nós com ela em seu registro discursivo altamente poético,

Os textos pós-coloniais estão no outro lado da margem do rio, em território alheio, apesar de uma ponte imaginária, que é a língua, nos unir, a ponte é a metáfora infinita, nunca mais acaba, quanto mais andamos, mais longe estamos, porque a ponte é ilusória e não é possível caminhar sobre a água, que nos escapa sempre, muito ou pouco, tal como a outra margem.

Em sua busca deliberada de mostrar a força simbólica dessa outra margem, a autora Ana Mafalda Leite, atendendo ao que Barthes preceitua, se entrega amorosamente aos objetos concretos que seu próprio prazer de leitora vai apontando.

Assim, pensando o "cânone moçambicano" em processo de consolidação, ela se debruça sobre as "configurações textuais da oralidade", principalmente em obras de Mia Couto e Paulina Chiziane, para, em processo final recolhitivo, analisar o que nomeia de "modelos no romance moçambicano". Nesse ensaio, ela considera, como diz, "a inscrição de modelos orais [...] um dos caminhos mais aliciantes, em via de instituição, na prática narrativa póscolonial". Mostra também como tais modelos "escapam a outros considerados canônicos". Retornam, nesse recorte dos modelos, as reflexões sobre Terra sonâmbula (1992) de Mia Couto e Sétimo juramento (2000) de Paulina Chiziane, ampliando-se a visada com Ualalapi de Ungulani Ba Ka Khosa que antecede os outros temporalmente - 1987 - e significa um dos marcos mais fortes do percurso ficcional moçambicano. A ensaísta demonstra que os "três romances são organizados a partir de uma estrutura narrativa oral de base, o conto", fazendo-se uma espécie de síntese alegórica do país, já que sua base são os "múltiplos contos, culturas e histórias" que, unidos na estrutura do gênero, que é o romance, ganham "sentido pleno".

O segmento subseqüente desvia o olhar do Índico para o Atlântico, aportando a ensaísta em Angola, mais precisamente ancorando seu barco no 
porto dos romances A gloriosa familia (1997) de Pepetela e A lenda dos bomens do vento, vol II, de Fernando Fonseca Santos - O tempo do meio (1998). Interessa-lhe perquirir no âmbito da escrita pós-colonial, a releitura da história colonial pelos dois textos e suas diferentes modelizações ou formulações. De certa forma, nesse gesto de leitura, a autora, respondendo, pela crítica, à proposta literária dos dois ficcionistas angolanos, ela e eles praticantes de uma cultura pós-colonial, parece atender ao convite do ensaísta Stuart Hall, de origem jamaicana, mas radicado na Inglaterra desde os anos 50, ou seja, convite para que haja um esforço "de juntar ao presente essas 'rotas' fragmentárias [...] e reconstruir suas genealogias não-ditas" preparando-se, desse modo, "o terreno histórico de que precisamos para conferir sentido à matriz interpretativa e às auto-imagens de nossa cultura, para tornar o invisível visível" (2003,0.42). Nesse sentido, as reflexões da autora não só respondem a Hall, mas se vão juntar a outras igualmente produtivas, como as de Inocência Mata, Luis Kandjimbo, Pires Laranjeira, Carlos Pacheco, Francisco Noa, Nelson Saúte, Gilberto Matusse e tantos outros, para além de vozes críticas brasileiras, de que sinto uma certa falta nos ensaios apresentados pela autora, já que, no Brasil, os estudos culturais em sua faceta pós-colonial vêm tentando, igualmente, “juntar essas 'rotas' fragmentárias” a que alude Hall, e que é a base do suplemento proposto pela leitura da ensaísta Ana Mafalda.

Por fim, a quarta e última parte de Literaturas Africanas e formulações póscoloniais nos traz as trilhas ou rotas da poesia moçambicana ou, no dizer da autora, seus percursos. Comparecem nessa ciranda poética proposta pela também poetisa Ana Mafalda, os textos de Luis Carlos Patraquim, Eduardo White, Virgílio de Lemos, Armando Artur, para além de Guita Júnior, Filimone Meigos, etc. Em especial pode-se ressaltar o ensaio" A reescrita de Caliban sobre a Ilha de Próspero", texto que em certo sentido "amarra" os demais e pelo qual ela tenta ler a ilha de Moçambique como "um dos espaços míticos de fundação da nação, enquanto espaço cultural". A ilha já aparecera no ensaio sobre Luis Carlos Patraquim, sendo mostrada como contribuindo para a travessia do poeta que tenta, dela partindo, ou da sua memória, formular "todas as ilhas literárias", formando um "arquipélago de tradição escolhida". Também o mar se reconvoca no último ensaio com a releitura do lugar do Índico por diversas vozes poéticas como as de White, Patraquim, Júlio Carrilho, etc, a que se acrescenta o lugar do céu, para que com eles, mar e 
céu, a própria crítica possa concluir sobre a importância de uma poesia que "faz circular o "sonho" de "uma espécie de pátria possível entre mar e céu, lugar em que homens e cultura convivem harmoniosamente", criando, como conclui, "uma nação poética, pátria em vôo e navegação".

Deliberadamente deixei para o fim o ensaio sobre Armando Artur onde a poetisa Ana Mafalda Leite quase toma o lugar da ensaísta firmemente ancorada na teorização do pós-colonial, para soltar as asas - e o último ensaio é também tributário disso - e, em "sonho e poesia", desvelar "O múltiplo rosto das imagens "que o seu texto, em ricochete com os de Armando Artur, nos revela. Ela, como ele, "tematiza o modo de captação do olhar e do tempo, em imagens 'refeitas' por dentro, em acto de transmutação, recriação". De certo modo, o que diz neste ensaio, costura o que pensa sobre o poeta e que de certo modo poderíamos estender para os autores e obras que seu texto ajuda, qual Penélope, a destecer para depois retecer, indefinida e intemporalmente. Fecho com suas palavras, para, parabenizando-a pela excelência de seu livro, dizer que recuperar as falas antigas soterradas pelo tempo e pela imposição dos vários silêncios culturais, no espaço literário africano, é tirar o véu que escondia "o múltiplo rosto das imagens", ou seja, tentar entender "o grande desafio" - e não posso esquecer António Jacinto que não só "anima o poeta [Armando Artur] à escuta das palavras", mas faz do escritor africano

um intérprete privilegiado das coisas que o rodeiam, sujeito e predicado que fala em simultâneo, com e pela linguagem

Parabéns, professora e poetisa Ana Mafalda Leite. O seu texto, fazendo-se também ele, "sujeito e predicado" a falar "com e pela linguagem", representa uma contribuição mais que efetiva para a consolidação da área por nós escolhida e que nos prende a todos qual Aracne em sua teia. 